\title{
Safety and continuity of second- and third-line therapy with paclitaxel or irinotecan for advanced and recurrent gastric cancer
}

\author{
MICHIO KIMURA $^{1}$, EISEKI USAMI ${ }^{1}$, TETSUFUMI KANEMATSU ${ }^{2}$, MINA IWAI $^{1}$, \\ TOMOAKI YOSHIMURA $^{1}$, HIROMI MORI ${ }^{1}$, TADASHI SUGIYAMA ${ }^{3}$ and HITOMI TERAMACHI ${ }^{4}$ \\ ${ }^{1}$ Department of Pharmacy, Ogaki Municipal Hospital, Ogaki, Gifu 503-8502; ${ }^{2}$ Department of Pharmacy, \\ Gifu Social Insurance Hospital, Kani, Gifu 509-0206; Laboratories of ${ }^{3}$ Pharmacy Practice and Social \\ Science and ${ }^{4}$ Clinical Pharmacy, Gifu Pharmaceutical University, Gifu, Gifu 501-1196, Japan
}

Received September 9, 2013; Accepted February 10, 2014

DOI: $10.3892 / \mathrm{mco} .2014 .260$

\begin{abstract}
In the treatment of advanced or recurrent gastric cancer, the prolongation of survival depends on the use of second-line therapy, with paclitaxel (PTX) or irinotecan (CPT-11) as the key agents. The present study aimed to retrospectively investigate the safety and continuity of weekly PTX and CPT-11 monotherapy as second- or third-line treatment for advanced or recurrent gastric cancer. A total of 62 patients who had received PTX or CPT-11 for gastric cancer at the Ogaki Municipal Hospital (Ogaki, Japan) were retrospectively reviewed. Of the 47 patients who received PTX as second-line therapy, $13(27.7 \%)$ received third-line therapy with CPT-11. Second-line PTX and third-line CPT-11 were discontinued due to progressive disease (PD) in 27 and 7 cases, respectively, and deterioration in the performance status (PS) in 20 and 4 cases, respectively. Only 1 case of discontinuation due to adverse events (AEs) was reported for third-line CPT-11. Furthermore, of the 15 patients who received CPT-11 as second-line treatment, $11(73.3 \%)$ then received PTX as third-line treatment. Second-line CPT-11 and third-line PTX were discontinued due to PD in 9 and 6 cases, respectively, and deterioration in the PS in 4 and 5 cases, respectively, whereas there was only 1 case of discontinuation due to AEs for second-line CPT-11. Severe AEs for PTX and CPT-11 were infrequent; however, the frequency of diarrhea was high when PTX was administered as third-line therapy (63.6\%), whereas the frequency of malaise was high when CPT-11 was administered as second- $(73.3 \%)$ and third-line (76.9\%) therapy. In conclusion, severe AEs due to PTX and CPT-11 as second- and third-line treatment for advanced or recurrent gastric cancer are infrequent and patients are generally able to continue treatment. However, the
\end{abstract}

Correspondence to: $\mathrm{Dr}$ Michio Kimura, Department of Pharmacy, Ogaki Municipal Hospital, 4-86 Minaminokawa, Ogaki, Gifu 503-8502, Japan

E-mail: kimkim0305nao@yahoo.co.jp

Key words: safety, continuity, paclitaxel, irinotecan, gastric cancer possibility of diarrhea with third-line PTX and malaise with second- and third-line CPT-11 treatment should be considered when planning chemotherapy.

\section{Introduction}

Tegafur-gimeracil-oteracil potassium (S-1) plus cisplatin is currently recommended as the standard first-line chemotherapy for advanced or recurrent gastric cancer in Japan, according to the results of the Japan Clinical Oncology Group 9912 (1) and those of the S-1 plus cisplatin vs. S-1 alone in randomized clinical trials for the first-line treatment of advanced gastric cancer (SPIRITS) trial (2). As regards second-line treatment, weekly paclitaxel (PTX) (3-9), irinotecan (CPT-11) monotherapy (10-15), S-1 plus PTX (16) and S-1 plus CPT-11 $(17,18)$ are used in daily practice. The prolongation of survival depends on the treatment following first-line therapy, with PTX and CPT-11 used as the key agents (19-21).

Akasaka et al (22) reported that tolerability to S-1 plus CPT-11 for advanced or recurrent gastric cancer differs between cases with a performance status (PS) of 2 and those with a PS of $0-1$. In addition, we previously reported a high frequency of adverse events (AEs) associated with S-1 plus cisplatin treatment or S-1 monotherapy in patients with a poor nutritional status $(23,24)$ and observed that a PS of $\geq 1$ and serum albumin levels (Alb) of $<3.5 \mathrm{~g} / \mathrm{dl}$ were risk factors for discontinuation of treatment due to AEs. Therefore, the tolerance to CPT-11 and PTX may decrease with deterioration of the patient's condition. In particular, we hypothesized that tolerance to chemotherapy decreases with the transition from second- to third-line therapy. However, the frequency of AEs and treatment continuity associated with second- and third-line chemotherapy with PTX or CPT-11 have not been sufficiently investigated. Therefore, this study aimed to retrospectively investigate the safety and continuity of PTX and CPT-11 as second- and third-line treatment for advanced or recurrent gastric cancer.

\section{Subjects and methods}

Patients and treatment. Between April, 2006 and March, 2013, 139 patients received S-1 plus cisplatin therapy as 
first-line treatment for advanced or recurrent gastric cancer at the Ogaki Municipal Hospital (Ogaki, Japan). In 62 of these cases, the patients later received CPT-11 or PTX as second- and third-line therapy. Data on treatment dose, PS, Alb, reasons for treatment discontinuation and frequency of AEs were retrospectively collected. The treatment dose was calculated as the ratio of the actual to the standard dose. All the data, such as treatment dose, PS and treatment duration, are presented as median value and range. Data on AEs, treatment dose, PS and reasons for discontinuation of chemotherapy were extracted from electronic charts and records of medication management and instructions completed by physicians. The severity of AEs was classified according to the Common Terminology Criteria for Adverse Events, version 4.0 .

This study was approved by the Institutional Review Board of the Ogaki Municipal Hospital.

Doses and routes of PTX and CPT-11. PTX was administered intravenously (i.v.) at a starting dose of $80 \mathrm{mg} / \mathrm{m}^{2}$ over $1 \mathrm{~h}$ weekly on days 1,8 and 15 over a 4 -week period. Irinotecan was administered i.v. at a starting dose of $150 \mathrm{mg} / \mathrm{m}^{2}$ over $1.5 \mathrm{~h}$ weekly on day 1 of each 2 -week period.

Statistical analysis. The Mann-Whitney U test was used for comparisons between two groups and comparisons among multiple groups were performed with one-factor analysis of variance. In all significance tests, $\mathrm{P}<0.05$ was considered to indicate a statistically significant difference.

\section{Results}

Patient characteristics. The patient characteristics are summarized in Table I. For the patients who received second-line PTX and CPT-11, the median age was 65 years (range, 49-79 years) and 66 years (range, $42-78$ years), respectively; unresectable tumors were identified in 35 and 4 cases and recurrent disease in 12 and 11 cases $(\mathrm{P}=0.0016)$, respectively. Peritoneal metastasis was identified in 26 and 2 patients who received second-line PTX and CPT-11, with a PS of 1 (range, $0-2$ ) and 0 (range, 0-2), respectively. Furthermore, the patients who received second-line PTX and CPT-11 had an Alb level of $3.7 \mathrm{~g} / \mathrm{dl}$ (range, 2.0-4.5 g/dl) and $4.1 \mathrm{~g} / \mathrm{dl}$ (range, 2.4-4.9 g/dl), respectively.

Reasons for discontinuation and AEs with second-and third-line therapy in patients who received second-line PTX. The reasons for treatment discontinuation and the AEs with second- and third-line treatment in patients who received second-line PTX are summarized in Tables II and III, respectively.

Rate of transition to third-line treatment. Of the 47 patients who received second-line PTX, 13 (27.7\%) later received third-line treatment.

Reasons for discontinuation. Second-line PTX or third-line CPT-11 were discontinued due to progressive disease (PD) in 27 and 7 cases, respectively and deterioration in the PS in 20 and 4 cases, respectively. Discontinuation due to AEs was reported in only 1 case of third-line CPT-11. That patient requested withdrawal of the treatment due to nausea.
Table I. Patient characteristics.

\begin{tabular}{ccc}
\hline & Second-line & Second-line \\
Characteristics & PTX $^{\mathrm{a}}(\mathrm{n}=47)$ & CPT-11 $^{\mathrm{b}}(\mathrm{n}=15)$ \\
\hline
\end{tabular}

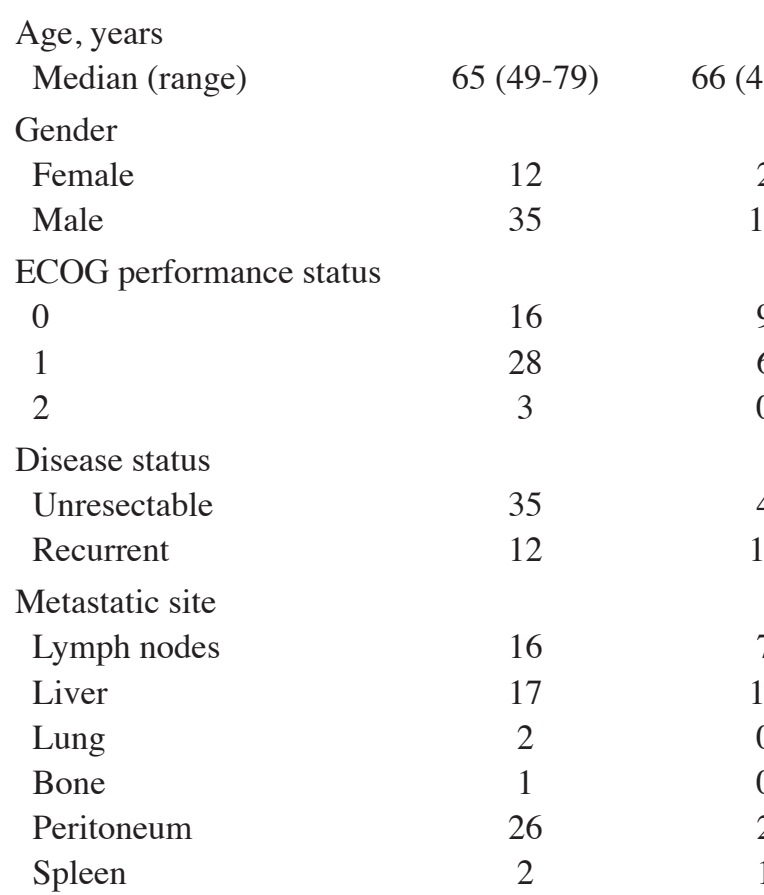

Treatment cycles (first-line)

$\begin{array}{lcc}1-2 & 7 & 2 \\ 3-4 & 11 & 5 \\ 5-6 & 13 & 3 \\ 7-8 & 7 & 3 \\ \geq 9 & 9 & 2\end{array}$

Others (range)

Performance status $\quad 1(0-2) \quad 0(0-2)$

Serum albumin level, g/dl $3.7(2.0-4.5) \quad 4.1(2.4-4.9)$

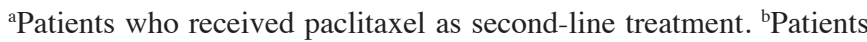
who received irinotecan as second-line treatment. PTX, paclitaxel; CPT-11, irinotecan; ECOG, Eastern Cooperative Oncology Group.

Duration of therapy and treatment dose. The duration of therapy was 120 days (range, 7-1,119 days) and 182 days (range, 28-497 days) and the median treatment dose was $100 \%$ (range, $60-100 \%$ ) and $100 \%$ (range, $80-100 \%$ ) for patients who received second-line PTX and third-line CPT-11, respectively.

$P S$ and serum Alb level. Patients who received second-line PTX and then third-line treatment had a PS of 1 (range, 0-1) and 1 (range, 0-2) and Alb levels of $3.7 \mathrm{~g} / \mathrm{dl}$ (range, 3.1-4.3 g/dl) and 3.5 g/dl (range, 2.3-4.3 g/dl), respectively, prior to the administration of second- and third-line treatment.

AEs. The AEs observed following second-line PTX included neutropenia (59.6\%), leukopenia (59.6\%), oligochromemia (76.6\%), sensory neuropathy $(76.6 \%)$ and constipation $(68.1 \%)$. The AEs observed with third-line CPT-11 included malaise (76.9\%) and oligochromemia (76.9\%). 
Table II. Reasons for discontinuation with second- and third-line therapy in patients who received second-line PTX.

A, Discontinuation following second-line CPT-11

\begin{tabular}{lcc}
\hline Variables & Second-line PTX ${ }^{\mathrm{a}}(\mathrm{n}=47)$ & Third-line CPT-11 $^{\mathrm{b}}(\mathrm{n}=13)$ \\
\hline Transition rate, $\%$ (n/total) & & $27.7(13 / 47)$ \\
Reason for discontinuation & 0 & 1 \\
Adverse events & 27 & 7 \\
Progressive disease & 20 & 4 \\
Decrease in PS & 0 & 1 \\
Other & $120(7-1,119)$ & $182(28-497)$ \\
Continuity period, days & $100(60-100)$ & $100(80-100)$ \\
Median (range) & & \\
Treatment dose, $\%$ & & \\
Median (range) & & \\
\hline
\end{tabular}

B, PS and serum Alb levels

\begin{tabular}{|c|c|c|c|c|}
\hline $\begin{array}{l}\text { PS and serum Alb } \\
\text { by treatment transition }\end{array}$ & $\begin{array}{c}\text { At the start of } \\
\text { second-line PTX }\end{array}$ & $\begin{array}{c}\text { At the end of } \\
\text { second-line PTX }\end{array}$ & $\begin{array}{l}\text { At the end of } \\
\text { third-line CPT-11 }\end{array}$ & P-values \\
\hline \multicolumn{5}{|l|}{ PS, value (range) } \\
\hline $\begin{array}{l}\text { Patients who transitioned } \\
\text { to third-line treatment }\end{array}$ & $1(0-1)$ & $1(0-2)$ & $2(0-3)$ & 0.0002 \\
\hline $\begin{array}{l}\text { Patients who stopped } \\
\text { at second-line treatment }\end{array}$ & $1(0-2)$ & $3(1-3)$ & - & $<0.0001$ \\
\hline \multicolumn{5}{|l|}{$\begin{array}{l}\text { Serum Alb level, } \\
\text { g/dl (range) }\end{array}$} \\
\hline $\begin{array}{l}\text { Patients who transitioned } \\
\text { to third-line treatment }\end{array}$ & $3.7(3.1-4.3)$ & $3.5(2.3-4.3)$ & $2.8(2.1-3.5)$ & 0.0014 \\
\hline $\begin{array}{l}\text { Patients who stopped } \\
\text { at second-line treatment }\end{array}$ & $3.8(2.0-4.5)$ & $2.9(2.1-4.1)$ & - & 0.0026 \\
\hline
\end{tabular}

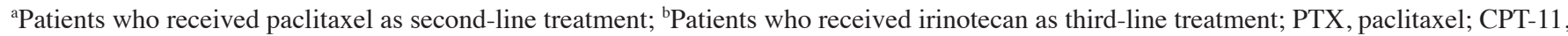
irinotecan; PS, performance status; Alb, albumin.

Reasons for discontinuation and AEs with second-and third-line therapy in patients who received second-line CPT-11. The reasons for discontinuation and the AEs associated with second- and third-line therapy in patients who received second-line CPT-11 are summarized in Tables IV and $\mathrm{V}$, respectively.

Rate of transition to third-line treatment. Of the 15 patients who received second-line CPT-11, $11(73.3 \%)$ then received third-line treatment.

Reasons for discontinuation. Second-line CPT-11 or third-line PTX was discontinued due to PD in 9 and 6 cases, respectively, and deterioration in the PS in 4 and 5 cases, respectively. Discontinuation due to AEs was reported in only 1 case following second-line CPT-11. That patient experienced anorexia and malaise.

Duration of therapy and treatment dose. The duration of therapy was 138 days (range, 28-566 days) and 110 days (range, 17-350 days) and the treatment dose was 100\% (range, $80-100 \%$ ) and $100 \%$ (range, $100-100 \%$ ) for patients who received second-line CPT-11 and third-line PTX, respectively.

$P S$ and serum Alb level. The patients who received second-line CPT-11 and then third-line treatment had a PS of 0 (range, 0-1) and 0 (range, 0-2) and Alb levels of $4.2 \mathrm{~g} / \mathrm{dl}$ (range, 3.2-4.9 g/dl) and $4.1 \mathrm{~g} / \mathrm{dl}$ (range, 3.2-4.8 g/dl), respectively, prior to second- and third-line treatment.

AEs. The AEs observed with second-line CPT-11 were mainly malaise $(73.3 \%)$ and nausea $(60.0 \%)$, whereas diarrhea $(63.6 \%)$ and sensory neuropathy $(63.6 \%)$ were commonly observed with third-line PTX (Table V).

Incidence of neutropenia with second-and third-line treatment in patients who transitioned to third-line treatment. A total of 15 patients experienced neutropenia with second-line treatment (PTX or CPT-11) and 5 patients experienced neutropenia with third-line treatment (PTX or CPT-11); the difference was found to be statistically significant $(\mathrm{P}=0.0039$; Table VI). 
Table III. Adverse events with second- and third-line therapy in patients who received second-line PTX.

\begin{tabular}{|c|c|c|c|c|}
\hline \multirow[b]{2}{*}{ Adverse events } & \multicolumn{2}{|c|}{ Second-line PTX ${ }^{\mathrm{a}}(\mathrm{n}=47)$} & \multicolumn{2}{|c|}{ Third-line CPT- $11^{\mathrm{b}}(\mathrm{n}=13)$} \\
\hline & All grades $(\%)$ & Grade $\geq 3(\%)$ & All grades $(\%)$ & Grade $\geq 3(\%)$ \\
\hline Leucopenia & $28(59.6)$ & $2(4.3)$ & $2(15.4)$ & $0(0.0)$ \\
\hline Neutropenia & $28(59.6)$ & $7(14.9)$ & $2(15.4)$ & $2(15.4)$ \\
\hline Oligochromemia & $36(76.6)$ & $2(4.3)$ & $10(76.9)$ & $1(7.7)$ \\
\hline Thrombocytopenia & $2(4.3)$ & $0(0.0)$ & $0(0.0)$ & $0(0.0)$ \\
\hline AST/ALT increase & $1(2.1)$ & $0(0.0)$ & $0(0.0)$ & $0(0.0)$ \\
\hline Febrile neutropenia & $3(6.4)$ & $3(6.4)$ & $1(7.7)$ & $1(7.7)$ \\
\hline Nausea & $9(19.1)$ & $0(0.0)$ & $5(38.5)$ & $0(0.0)$ \\
\hline Vomiting & $5(10.6)$ & $0(0.0)$ & $4(30.8)$ & $0(0.0)$ \\
\hline Malaise & $27(57.4)$ & $0(0.0)$ & $10(76.9)$ & $1(7.7)$ \\
\hline Diarrhea & $4(8.5)$ & $0(0.0)$ & $7(53.8)$ & $0(0.0)$ \\
\hline Anorexia & $23(48.9)$ & $1(2.1)$ & $8(61.5)$ & $1(7.7)$ \\
\hline Stomatitis & $4(8.5)$ & $0(0.0)$ & $1(7.7)$ & $0(0.0)$ \\
\hline Sensory neuropathy & $36(76.6)$ & $1(2.1)$ & $8(61.5)$ & $0(0.0)$ \\
\hline Constipation & $32(68.1)$ & $0(0.0)$ & $9(69.2)$ & $0(0.0)$ \\
\hline Taste alteration & $7(14.9)$ & $0(0.0)$ & $1(7.7)$ & $0(0.0)$ \\
\hline Infusion site extravasation & $1(2.1)$ & $0(0.0)$ & $0(0.0)$ & $0(0.0)$ \\
\hline Arthralgia & $1(2.1)$ & $0(0.0)$ & $0(0.0)$ & $0(0.0)$ \\
\hline Hot flushes & $1(2.1)$ & $0(0.0)$ & $0(0.0)$ & $0(0.0)$ \\
\hline Edema & $2(4.3)$ & $0(0.0)$ & $5(38.5)$ & $0(0.0)$ \\
\hline Nail discoloration & $4(8.5)$ & $0(0.0)$ & $0(0.0)$ & $0(0.0)$ \\
\hline Other & $1(2.1)$ & $0(0.0)$ & $0(0.0)$ & $0(0.0)$ \\
\hline
\end{tabular}

aPatients who received paclitaxel as second-line treatment; 'Patients who received irinotecan as third-line treatment; PTX, paclitaxel; CPT-11, irinotecan; AST, aspartate aminotransferase; ALT, alanine aminotransferase.

\section{Discussion}

CPT-11 and PTX as second- and third-line chemotherapies are currently the most effective treatments for advanced or recurrent gastric cancer (19); however, the tolerability to treatment may be reduced, depending on the condition of the patients (22-24). The findings of 4,007 comparative phase III trials of PTX and CPT-11 as second-line treatment for advanced gastric cancer, conducted by the West Japan Oncology Group (WJOG; WJOG4007) were reported at the American Society of Clinical Oncology meeting in 2012 (25). Ueda et al (25) reported that the rate of transition from second- to third-line treatment was higher with second-line CPT-11 (90\%) compared to that with second-line PTX (72\%).

In our study, the patients who received second-line PTX exhibited a lower transition rate from second- to third-line treatment $(27.7 \%)$. As regards PS and Alb levels prior to second-line treatment, the general condition of the patients who received second-line PTX was poor prior to second-line chemotherapy. PTX is often selected for patients with peritoneal dissemination, which was frequently the case in the present study. Therefore, we hypothesized that the transition from second- to third-line treatment may be difficult for patients who receive second-line PTX. However, in the WJOG4007 trials, patients with extensive peritoneal dissemination were excluded (25). Accordingly, the difference in the rate of transition to third-line treatment between the present study and the WJOG4007 trials is likely be due to differences between the clinical trial setting and the actual clinical setting.

The discontinuation of second- and third-line treatment (Table II) were commonly due to PD and a decrease in the PS, whereas discontinuation due to AEs was observed in only 1 case. Additionally, the majority of treatment doses were $100 \%$ in the patients who received second-line PTX or third-line CPT-11 and the general condition of the patients who transitioned to third-line treatment was poor; however, in this study, the incidence of severe AEs was low. Accordingly, we considered second-line PTX and third-line CPT-11 to be tolerable and patients may successfully continue treatment in the actual clinical setting.

As regards AEs following second-line PTX and third-line CPT-11 in patients who received second-line PTX, the frequency of malaise was high (76.9\%) with third-line CPT-11. Although malaise is not commonly considered to be a severe $\mathrm{AE}$, it may be perceived as severe if the general condition of the patient is poor. For second-line PTX and third-line CPT-11, the frequency of oligochromemia was high $(\sim 77 \%)$; however, 
Table IV. Reasons for discontinuation with second- and third-line therapy in patients who received second-line CPT-11.

A, Discontinuation following second-line CPT-11

\begin{tabular}{lcc}
\hline Variables & Second-line CPT-11 $(\mathrm{n}=15)$ & Third-line PTX $^{\mathrm{b}}(\mathrm{n}=11)$ \\
\hline Transition rate, $\%$ (n/total) & $73.3(11 / 15)$ & 0 \\
Reason for discontinuation & 1 & 6 \\
Adverse events & 9 & 5 \\
Progressive disease & 4 & 0 \\
Decrease in PS & 1 & $110(17-350)$ \\
Others & $138(28-566)$ & $100(100-100)$ \\
Continuity period, days & $100(80-100)$ & \\
Median (range) & & \\
Treatment dose, $\%$ & & \\
Median (range) & & \\
\hline
\end{tabular}

$\mathrm{B}, \mathrm{PS}$ and serum Alb levels

\begin{tabular}{|c|c|c|c|c|}
\hline $\begin{array}{l}\text { PS and serum Alb } \\
\text { by treatment transition }\end{array}$ & $\begin{array}{c}\text { At the start of } \\
\text { second-line CPT-11 }\end{array}$ & $\begin{array}{c}\text { At the end of } \\
\text { second-line CPT-11 }\end{array}$ & $\begin{array}{l}\text { At the end of } \\
\text { third-line CPT-11 }\end{array}$ & P-values \\
\hline \multicolumn{5}{|l|}{ PS, value (range) } \\
\hline $\begin{array}{l}\text { Patients who transitioned } \\
\text { to third-line treatment }\end{array}$ & $0(0-1)$ & $0(0-2)$ & $2(0-3)$ & $<0.0001$ \\
\hline $\begin{array}{l}\text { Patients who stopped } \\
\text { at second-line treatment }\end{array}$ & $0(0-2)$ & $3(1-3)$ & - & $<0.0001$ \\
\hline \multicolumn{5}{|l|}{$\begin{array}{l}\text { Serum Alb level, } \\
\text { g/dl (range) }\end{array}$} \\
\hline $\begin{array}{l}\text { Patients who transitioned } \\
\text { to third-line treatment }\end{array}$ & $4.2(3.2-4.9)$ & $4.1(3.2-4.8)$ & $3.1(2.1-4.5)$ & 0.0014 \\
\hline $\begin{array}{l}\text { Patients who stopped } \\
\text { at second-line treatment }\end{array}$ & $3.4(2.4-4.2)$ & $2.9(2.6-3.4)$ & - & 0.2217 \\
\hline
\end{tabular}

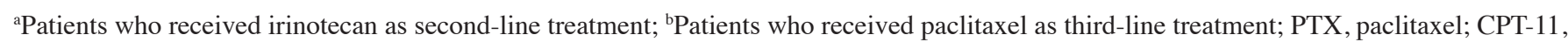
irinotecan; PS, performance status; Alb, albumin.

this may be attributed to the waning nutritional status of pretreated patients.

In the patients who received second-line CPT-11, the rate of transition from second- to third-line treatment $(73.3 \%)$ was comparable to that reported in the WJOG4007 study (Table IV). Furthermore, in a previous study conducted by Kawamura et al (11), it was reported that if the AEs are mild and the PS is good, third-line treatment is appropriate. In the present study, based on the Alb levels and the PS, the general condition of the patients who were unable to transition to third-line treatment was considered to be poor prior to second-line chemotherapy. In addition, during third-line CPT-11, the general condition of the patients was considered to have further deteriorated.

The majority of the treatment doses were $100 \%$ in the patients who received second-line CPT-11 or third-line PTX and severe AEs were infrequent with second-line CPT-11 and third-line PTX, whereas discontinuation due to AEs was reported in only 1 case. A previous study by Farhat (15) reported that hematological and digestive toxicities were tolerable and mild with irinotecan-based chemotherapy, particularly with a weekly regimen. Therefore, CPT-11 as second-line and PTX as third-line treatment are considered to be tolerable and patients may successfully continue treatment in the clinical setting.

As regards AEs following second-line CPT-11 and third-line PTX in patients who received second-line CPT-11, the frequency of malaise was found to be high (73.3\%) with second-line CPT-11, similar to that for third-line CPT-11 in patients who received second-line PTX. The frequency of diarrhea with PTX was higher in the third-line $(63.6 \%)$ compared to that in the second-line setting (8.5\%), possibly due to disease progression.

In the patients who received PTX or CPT-11 as second-line treatment and transitioned to third-line treatment, neutropenia was more frequently observed during second-line compared to that during third-line treatment; these patients were not administered a reduced dose during third-line treatment. A previous study by Shitara et al (26) reported a correlation 
Table V. Adverse events with second- and third-line therapy in patients who received second-line CPT-11.

\begin{tabular}{|c|c|c|c|c|}
\hline \multirow[b]{2}{*}{ Adverse events } & \multicolumn{2}{|c|}{ Second-line CPT-11 ${ }^{\mathrm{a}}(\mathrm{n}=15)$} & \multicolumn{2}{|c|}{ Third-line $\mathrm{PTX}^{\mathrm{b}}(\mathrm{n}=11)$} \\
\hline & All grades $(\%)$ & Grade $\geq 3(\%)$ & All grades $(\%)$ & Grade $\geq 3(\%)$ \\
\hline Leucopenia & $8(53.3)$ & $1(6.7)$ & $3(27.3)$ & $0(0.0)$ \\
\hline Neutropenia & $8(53.3)$ & $0(0.0)$ & $3(27.3)$ & $0(0.0)$ \\
\hline Oligochromemia & $8(53.3)$ & $0(0.0)$ & $6(54.5)$ & $1(9.1)$ \\
\hline Thrombocytopenia & $1(6.7)$ & $0(0.0)$ & $1(9.1)$ & $0(0.0)$ \\
\hline AST/ALT increase & $1(6.7)$ & $1(6.7)$ & $0(0.0)$ & $0(0.0)$ \\
\hline Febrile neutropenia & $0(0.0)$ & $0(0.0)$ & $0(0.0)$ & $0(0.0)$ \\
\hline Nausea & $9(60.0)$ & $0(0.0)$ & $5(45.5)$ & $0(0.0)$ \\
\hline Vomiting & $2(13.3)$ & $0(0.0)$ & $4(36.4)$ & $0(0.0)$ \\
\hline Malaise & $11(73.3)$ & $0(0.0)$ & $5(45.5)$ & $1(9.1)$ \\
\hline Diarrhea & $5(33.3)$ & $0(0.0)$ & $7(63.6)$ & $0(0.0)$ \\
\hline Anorexia & $6(40.0)$ & $0(0.0)$ & $3(27.3)$ & $1(9.1)$ \\
\hline Stomatitis & $3(20.0)$ & $0(0.0)$ & $0(0.0)$ & $0(0.0)$ \\
\hline Sensory neuropathy & $4(26.7)$ & $0(0.0)$ & $7(63.6)$ & $0(0.0)$ \\
\hline Constipation & $6(40.0)$ & $0(0.0)$ & $5(45.5)$ & $0(0.0)$ \\
\hline Taste alteration & $1(6.7)$ & $0(0.0)$ & $1(9.1)$ & $0(0.0)$ \\
\hline Infusion site extravasation & $0(0.0)$ & $0(0.0)$ & $1(9.1)$ & $0(0.0)$ \\
\hline Arthralgia & $0(0.0)$ & $0(0.0)$ & $1(9.1)$ & $0(0.0)$ \\
\hline Hot flushes & $0(0.0)$ & $0(0.0)$ & $0(0.0)$ & $0(0.0)$ \\
\hline Edema & $1(6.7)$ & $0(0.0)$ & $1(9.1)$ & $0(0.0)$ \\
\hline Nail discoloration & $0(0.0)$ & $0(0.0)$ & $0(0.0)$ & $0(0.0)$ \\
\hline Other & $0(0.0)$ & $0(0.0)$ & $2(18.2)$ & $0(0.0)$ \\
\hline
\end{tabular}

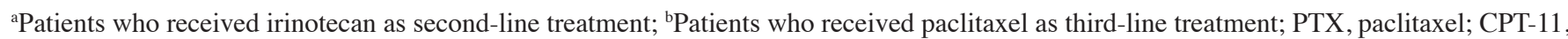
irinotecan; AST, aspartate aminotransferase; ALT, alanine aminotransferase.

Table VI. Incidence of neutropenia with second- and third-line treatment in patients who transitioned to third-line treatment.

\begin{tabular}{|c|c|c|c|c|c|c|}
\hline \multirow[b]{2}{*}{ Neutropenia } & \multicolumn{2}{|c|}{ Second-line PTX $^{\mathrm{a}}$} & \multicolumn{2}{|c|}{ Second-line CPT- $11^{\mathrm{b}}$} & \multicolumn{2}{|c|}{ Total } \\
\hline & $\begin{array}{l}\text { Second-line } \\
\text { PTX }\end{array}$ & $\begin{array}{l}\text { Third-line } \\
\text { CPT-11 }\end{array}$ & $\begin{array}{l}\text { Second-line } \\
\text { CPT-11 }\end{array}$ & $\begin{array}{l}\text { Third-line } \\
\text { PTX }\end{array}$ & $\begin{array}{c}\text { Second-line } \\
\text { treatment }\end{array}$ & $\begin{array}{l}\text { Third-line } \\
\text { treatment }\end{array}$ \\
\hline Presence & 10 & 2 & 5 & 3 & 15 & 5 \\
\hline Absence & 3 & 11 & 7 & 9 & 10 & 20 \\
\hline P-values & \multicolumn{2}{|c|}{0.0016} & \multicolumn{2}{|c|}{0.3864} & \multicolumn{2}{|c|}{$\mathrm{P}=0.0039$} \\
\hline
\end{tabular}

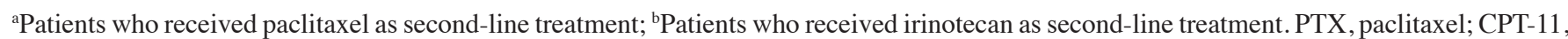
irinotecan.

between prognosis and the occurrence of neutropenia in patients receiving PTX as second-line treatment. Similarly, there may exist a correlation between prognosis and neutropenia for third-line treatment; therefore, we consider this to be an important focus of future investigations.

In conclusion, second- or third-line treatment with PTX or CPT-11 for patients with advanced or recurrent gastric cancer has been associated with a low incidence of severe AEs and the patients were able to successfully continue treatment. However, the incidence of diarrhea during treatment with PTX in the third-line setting and that of malaise during treatment with CPT-11 in the second- and third-line setting must be carefully considered when planning chemotherapy for such patients. 


\section{References}

1. Boku N, Yamamoto S, Fukuda H, et al; Gastrointestinal Oncology Study Group of the Japan Clinical Oncology Group: Fluorouracil versus combination of irinotecan plus cisplatin versus S-1 in metastatic gastric cancer: a randomised phase 3 study. Lancet Oncol 10: 1063-1069, 2009.

2. Koizumi W, Narahara H, Hara T, et al: S-1 plus cisplatin versus S-1 alone for first-line treatment of advanced gastric cancer (SPIRITS trial): a phase III trial. Lancet Oncol 9: 215-221, 2008.

3. Shitara K, Oze I, Mizota A, et al: Randomized phase II study comparing dose escalated weekly paclitaxel vs. standard dose weekly paclitaxel for patients with previously treated advanced gastric cancer. Jpn J Clin Oncol 41: 287-290, 2011.

4. Shimoyama R, Yasui H, Boku N, et al: Weekly paclitaxel for heavily treated advanced or recurrent gastric cancer refractory to fluorouracil, irinotecan, and cisplatin. Gastric Cancer 12: 206-211, 2009.

5. Hironaka S, Zenda S, Boku N, Fukutomi A, Yoshino T and Onozawa Y: Weekly paclitaxel as second-line chemotherapy for advanced or recurrent gastric cancer. Gastric Cancer 9: 14-18, 2006

6. Egawa T, Kubota T, Nagashima A, Doi M, Kitano M, Hayashi S, Yoshii H, Saikawa Y and Kitajima M: Usefulness of weekly administration of paclitaxel for advanced or recurrent gastric cancer. Jpn J Canc Chemother 31: 877-881, 2004 (In Japanese).

7. Koizumi W, Akiya T, Sato A, Yamaguchi K, Sakuyama T, Nakayama N, Tanabe S, Higuchi K, Sasaki T and Sekikawa T; Tokyo Cooperative Oncology Group (TCOG GI Group): Second-line chemotherapy with biweekly paclitaxel after failure of fluoropyrimidine-based treatment in patients with advanced or recurrent gastric cancer: a report from the gastrointestinal oncology group of the Tokyo Cooperative Oncology Group, TCOG GC-0501 trial. Jpn J Clin Oncol 39: 713-719, 2009.

8. Matsuda G, Kunisaki C, Makino H, et al: Phase II study of weekly paclitaxel as a second-line treatment for S-1-refractory advanced gastric cancer. Anticancer Res 29: 2863-2867, 2009.

9. Kodera Y, Ito S, Mchizuki Y, et al; Chubu Clinical Cancer Group: A phase II study of weekly paclitaxel as second-line chemotherapy for advanced gastric cancer (CCOG0302 study). Anticancer Res 27: 2667-2671, 2007.

10. Chun JH, Kim HK, Lee JS, Choi JY, Lee HG, Yoon SM, Choi IJ, Ryu KW, Kim YW and Bae JM: Weekly irinotecan in patients with metastatic gastric cancer failing cisplatin-based chemotherapy. Jpn J Clin Oncol 34: 8-13, 2004.

11. Kawamura H, Yokota R, Watarai H, et al: Third-line CPT-11 chemotheraphy for gastric cancer cases of non-curative gastrectomy or recurrence. Jpn J Canc Chemother 37: 1051-1054, 2010 (In Japanese).

12. Kuculzeybek Y, Dirican A, Erten C, Somali I, Can A, Demir L, Bayoglu IV, Akyol M, Medeni M and Tarhan MO: Second-line irinotecan after cisplatin, fluoropyrimidin and docetaxel for chemotherapy of metastatic gastric cancer. Asian Pac J Cancer Prev 13: 2771-2774, 2012.

13. Oda H, Mizuno T, Yamashita Y, Nomura H, Saito K, Tamaru S, Kageyama $\mathrm{S}$ and Katayama $\mathrm{N}$ : Irinotecan as second-line chemotherapy for 5-FU-resistant gastric cancer with disseminated intravascular coagulation: a case report. Jpn J Canc Chemother 38: 1517-1520, 2011 (In Japanese).
14. Goto A, Sukawa Y, Igarashi H, et al: Irinotecan as the key chemotherapeutic agent in second-line treatment of metastatic gastric cancer after failure of first-line S-1 or S-1/CDDP therapy. Jpn J Canc Chemother 38: 1461-1466, 2011 (In Japanese).

15. Farhat FS: A general review of the role of irinotecan (CPT11) in the treatment of gastric cancer. Med Oncol 24: 137-146, 2007.

16. Fujitani K, Narahara H, Takiuchi H, Tsujinaka T, Satomi E, Gotoh M, Hirao M, Furukawa $\mathrm{H}$ and Taguchi T: Phase I and pharmacokinetic study of S-1 combined with weekly paclitaxel in patients with advanced gastric cancer. Oncology 69: 414-420, 2005.

17. Kumagai K, Saikawa Y, Nakamura R, Takahashi T, Kubota T, Kumai K, Kitagawa Y and Kitajima M: Clinical experience of second-line chemotherapy with S-1/CPT-11 for highly advanced gastric cancer. Jpn J Canc Chemother 35: 245-250, 2008 (In Japanese)

18. Komatsu Y, Yuki S, Fuse N, et al: Phase 1/2 clinical study of irinotecan and oral S-1 (IRIS) in patients with advanced gastric cancer. Adv Ther 27: 483-492, 2010.

19. Shitara K, Matsuo K, Mizota A, et al: Association of fluoropyrimidines, platinum agents, taxanes, and irinotecan in any line of chemotherapy with survival in patients with advanced gastric cancer. Gastric Cancer 14: 155-160, 2011.

20. Thuss-Patience PC, Kretzschmar A, Bichev D, Deist T, Hinke A, Breithaupt K, Dogan Y, Gebauer B, Schumacher G and Reichardt P: Survival advantage for irinotecan versus best supportive care as second-line chemotherapy in gastric cancer - a randomized phase III study of the Arbeitsgemeinschaft Internistische Onkologie (AIO). Eur J Cancer 47: 2306-2314, 2011.

21. Kang JH, Lee SI, Lim do H, et al: Salvage chemotherapy for pretreated gastric cancer: a randomized phase III trial comparing chemotherapy plus best supportive care with best supportive care alone. J Clin Oncol 30: 1513-1518, 2012.

22. Akasaka O, Iwase S, Miwa H, Ando T, Morita S, Koh R, Kasama M, Matsueda R and Anan H: Combination chemotherapy of S-1 and CPT-11 for advanced recurrent gastric cancer. Jpn J Canc Chemother 36: 1833-1837, 2009 (In Japanese).

23. Kimura M, Usami E,Okada K,Nakao T, Yoshimura T and Yasuda T: Safety evaluation for chemotherapy with $\mathrm{S}-1$ and cisplatin based on nutrition factors using body mass index and serum albumin levels in patients with advanced and recurrent gastric cancer. J Jpn Soc Hosp Pharm 45: 785-788, 2009 (In Japanese).

24. Kimura M, Morihata K, Ito D, Iwai M, Okada K, Usami E, Nakao T, Yoshimura T and Yasuda T: Continuous administration and safety of S-1 in adjuvant chemotherapy for gastric cancer. Jpn J Canc Chemother 37: 829-834, 2010 (In Japanese).

25. Ueda S, Hironaka S, Yasui H, et al: Randomized phase III study of irinotecan (CPT-11) versus weekly paclitaxel (wPTX) for advanced gastric cancer (AGC) refractory to combination chemotherapy (CT) of fluoropyrimidine plus platinum (FP): WJOG4007 trial. J Clin Oncol 30 (American Society of Clinical Oncology, 48th Annual Meeting): abs. 4002, 2012.

26. Shitara K, Matsuo K, Takahari D, et al: Neutropenia as a prognostic factor in advanced gastric cancer patients undergoing second-line chemotherapy with weekly paclitaxel. Ann Oncol 21: 2403-2409, 2010. 